\title{
Economic Decline, Health Worker Migration and its Impact on Female Workload in Zimbabwe
}

\author{
Ignatius Gutsa (Mr) \\ Lecturer, Sociology Department, University of Zimbabwe, P.O Box MP167, Mt Pleasant, \\ Harare, Zimbabwe \\ E-mail: gnatsio@gmail.com \\ Naume Zorodzai Choguya \\ Lecturer, Sociology Department, University of Zimbabwe, P.O Box MP167, Mt Pleasant, \\ Harare, Zimbabwe \\ E-mail: zchoguya@gmail.com
}

Accepted: May 17, 2012 Published: June 27, 2012

Doi:10.5296/jsr.v3i2.2412 URL: http://dx.doi.org/10.5296/jsr.v3i2.2412

\begin{abstract}
This paper explores the implications of Home Based Care on women's workload in the context of high HIV and AIDS prevalence rates in Zimbabwe as the country has experienced serious health worker migration since 2000. Health worker migration in Zimbabwe as a result of the weak performance of the economy over the years has inadvertently increased women's workload as more and more people adopt Home Based Care for their terminally ill family members suffering from HIV and AIDS. Home-based care has been one of the most effective community care strategies in Zimbabwe for people living with HIV and AIDS. To explore this state of affairs the paper adopted the theory of reflexive modernity which argues that the progressive freeing of the agency from structure has the effect of releasing people from the inherent constrains of the socio-structural tradition of modernity. The conclusion is that in the Zimbabwean context were women are viewed as the 'natural' care givers reflexive modernity may fail to apply as increased health worker migration is increasing women's workload as more women are involved in Home Based Care in the context of high HIV and AIDS prevalence rates.
\end{abstract}

Keywords: Women, HIV and AIDS, Home based care, reflexive modernity, Zimbabwe

\section{Introduction and Background}

This paper examines the impact of Home Based Care (HBC) on women's workload in the face of HIV and AIDS and high health worker migration as a result of the weak performance 
of the Zimbabwe economy over the course of more than a decade. The Zimbabwean population has been hugely affected by the HIV pandemic with current prevalence rates hovering at around 17 per cent. Although this has fallen dramatically from around 26 per cent in 2003 the prevalence rates are still too high (Bildenberg et al, 2008, 29). HIV and AIDS is still causing massive problems and is responsible for a large number of deaths in the country. It has led to life expectancy falling to 34 years for women, and 37 years for men, the lowest rates in the world. The challenges in the economy and consequently the health sector began in the early 1990s with the adoption of neo-liberal economic policies in the form of the Economic Structural Adjustment Program (ESAP). The principles behind ESAP were the privatisation of social services. The result was that with the adoption of ESAP, the state had to retreat from the health sector among other sectors where it was providing subsidies to its citizens. As a result the private sector's principle of profit reigned supreme as more and more private health providers entered the once regulated space. Over the years Zimbabwe's experienced health workers and other professionals have been migrating to look for better working conditions in the region and abroad as a result of poor remuneration and working conditions.

Up until the formation of the Government of National Unity (GNU) on the $13^{\text {th }}$ of February 2009 following the power sharing agreement between President Robert Mugabe's Zimbabwe African National Union Patriotic Front (ZANU PF), Prime Minister Morgan Tsvangirai's Movement for Democratic Change (MDC T), and Deputy Prime Minister Arthur Mutambara's MDC M, the economic situation in Zimbabwe had been characterised by a hyper inflationary spiral which was highest for a country not at war. The ZANU PF government blamed illegal sanctions for the inflationary spiral while other quaters blamed it on mismanagement by the government as it had inherited a robust economy in 1980 at attainment of independence from British rule. Even though Zimbabwe has since stopped using the Zimbabwe dollar in favour of a multi currency regime since the formation of the GNU, the prevailing weak economy has made health care costs to be out of reach of reach for most people as workers' savings are not capable of absorbing these costs. Even well established medical aid societies are facing a very serious challenge to cope with the increasing claims costs.

As a result of the above challenges more and more HIV and AIDS patients in the terminal and most taxing stage of the illness are currently taking up Home Based Care. According to Government of Zimbabwe $(2010,10)$ the practice of Community Home Based Care has been in existence for several decades. In Zimbabwe structured community home based care targeting individuals with chronic illnesses such as cancer, hypertension and its complications, diabetes, epilepsy, mental illness has existed for close to three decades. As has been noted by many studies, in an economic downturn women tend to suffer more and more as their workload increases. Hence their economic, educational and career aspirations suffer in the process as they are the first ones to be withdrawn from these sectors to provide care to their kin mainly in the African context as they are presumed to be the natural caregivers. According to the Proposed Code for the Southern African Development Community 
(ARASA, 2004. 10) throughout much of SADC the position of women in society and within families is such that they are expected among other duties to being the primary caregivers to children and men. Therefore it can be observed that this expectation and the reality on the ground in Africa in the face of HIV and AIDS does run counter to propositions by advocates of reflexive modernity like Beck $(1992,135)$ who argue that

“...people are being released from the constraints of gender -------men and women are released from traditional forms of ascribed roles."

\section{The Face of HIV and Aids}

Worldwide there are almost forty million people living with HIV and AIDS with four million infections each year. The number of people dying from AIDS worldwide increased to 2, 9 million in 2006 and prevention measures are failing to keep pace with the growth of the epidemic (Developments, 2008). In 2005 more than 15million children had lost one or both parents. According to the International Federation of the Red Cross and Red Crescent in its 2008 World Disasters Report at least one person in ten is living with HIV in nations such as South Africa, Zimbabwe, Botswana, Lesotho, Malawi, Zambia, Namibia, Mozambique and Swaziland (The Herald, 2008). The consequences of the epidemic are felt by all of society and not just those who are sick due to the economic strain and social tensions that result. For example the infected withdraw from the labour market and school to seek treatment. Affected women, also withdraw to care for the infected and affected as well as adopting livelihood strategies to help the family cope. Furthermore Kachere $(2008,4)$ also notes that Africa especially sub-Saharan Africa has the highest number of infected health care workers. This therefore affects the capacity of the health system to effectively cater for the HIV and AIDS patients seeking services from it.

\section{The State Of Health Worker Migration In Zimbabwe}

Developments $(2007,25)$ observed that the world's poorest countries are suffering from a punishing exodus of their most talented, experienced and educated citizens. Around a million skilled people from officially designated Least Developed Countries (LDCs) lived and worked in developed countries in 2004. This represented a brain drain of some 15 per cent of people with university level education. The global shortage of health workers is estimated to be four million by 2015. A study commissioned by IOM $(2010,12)$ noted that there was a critical shortage of staff in the medical field in Zimbabwe. A review of evidence from the Ministry of Health and Child Welfare figures for December 2008 showed that Zimbabwe had 1.7 health workers per 1000 people, which is below World Health Organization (WHO) Africa regional average of 2.6 per 1000 people. The critical shortage of staff gave a gloomy picture of Zimbabwe's doctor patient ratio of 0.16 doctors per 1000 people compared to 0.22 doctors per 1000 patients in Africa on average. IOM (2010, 29) further noted that the majority of health professionals in Zimbabwe migrated mainly for socio-economic and political reasons, self advancement, to further their education as well as seeking better 
working conditions and study opportunities for dependants. Further, a considerable number of health professionals in the diaspora have realized their goal for emigrating as they are better remunerated, have assumed more senior responsibilities and have undergone specialist training after leaving Zimbabwe.

\section{Women, Care giving and HIV and Aids in Zimbabwe}

Although it is widely acknowledged that the whole Zimbabwean nation is currently plagued with vulnerability to both poverty and the HIV and AIDS epidemic there are groups that are disproportionately affected by both hardships in a vicious cycle, namely youths, women, children, the elderly, the disabled and those residing in rural areas. There are several reasons why this is so ranging from historical factors to the organisation of economic systems etc (ZHDR, 2003, 30). As acknowledged by Ogden et al (2006, 333)

"Many indigenous social safety nets that underpinned the care economy in the pre-AIDS era and that enabled many households to remain viable in times of crisis are being eroded in highly affected communities."

According to ARASA (2004) women are the ones who are the primary caregivers in Africa thereby reflecting the gendered nature of care in Africa. As ARASA $(2004,11)$ notes inequitable economic policies and the failure by governments to plan and allocate resources and support structures to cope with the pressures exerted by the AIDS pandemic have transferred much of the burden of care for the ill and dying from public facilities to the home and therefore to women. Kakuru (2007) observed that the impact of HIV and AIDS on rural livelihoods also reinforces discrimination against girls as AIDS increases household tasks whilst at the same time decreasing labour and income through illness and death. The result is that children fill these gaps and girls are more affected than boys. HIV and AIDS also widen the existing inequalities of access to education for boys and girls (Ibid). HelpAge (1992) also noted that research in several African countries showed that the poorest older women, in this case rural grandmothers have taken the responsibility of caring for the most vulnerable in their communities that is children and grandchildren with HIV and AIDS in the absence of any state support.

This situation is therefore creating an environment where households and ultimately women shoulder the burden of taking care of those suffering from HIV and AIDS. Furthermore in respect of women, the Zimbabwe Human Development Report $(2003$, 38) noted that the social ideology of feminity and masculinity goes even further to define gender roles in society. One such outstanding role pertains to

'...women as the natural caregivers in the home."

As a result under the current HIV and AIDS epidemic mode in Zimbabwe given the general resource constraints on the part of the state as a result of a number of factors ranging from 
after effects of ESAP and the generally weak and non performing economy this has meant that women are bearing the brunt of caring for the sick under HBC and the growing number of orphaned children with very little or no extra help to make this task manageable. ZHDR (2003, 156) further states that; "Home Based Care becomes a subsidy for cash strapped hospitals in the face of neo-liberal policies and their emphasis on cost recovery. The current economic crisis has meant that people have to spend a lot of time searching for and queuing for food. Most likely this task will be reserved for women." Generally economic circumstances are also impacting on gender roles and more and more women are entering the workforce thereby reducing further the number of potential caregivers. HelpAge $(1992,102)$ also noted that the traditional care system has been the responsibility of the females in families. The majority of younger women have no choice but to enter the workforce.

\section{Reflexive Modernity and Families under Transition}

According to Beck and Beck (1996) theories of reflexive modernity propose a detraditionalisation of the social and as a consequence celebration of increasing individualisation where rather than being a matter of social determination, class, gender, sexuality and even life and death are more a matter of individual decisions as social actors are given the capacity to affect change. HelpAge $(1996,99)$ further notes that just like everything else, the family is experiencing changes which include demographic, socio-economic and cultural. These changes are causing the need for adaptation and innovation by families and communities in how they meet their traditional roles and functions.

\section{Understanding Home Based Care in Zimbabwe}

As noted by Mundia $(2008,21)$ 'Home-Based Care is care given to ill people in their home. This care is provided by relatives, friends and/or community volunteers working for a non-governmental organization (NGO).' Launched in 1992 the concept of home-based-care for HIV and Aids patients was hailed as the panacea for taking care of the individuals with AIDS. This care usually includes physical, psychological, palliative, and spiritual activities that aim to promote, restore and maintain a person's maximum level of comfort, function and health, including care towards a dignified death. Considering that women are assumed as the natural caregivers in most African countries it can therefore be noted that this then could be having a negative impact on women in Zimbabwe as they are the assumed natural caregivers in the context of HIV and AIDS. The ZHDR report $(2003,155)$ noted that in keeping with the National Aids Council Policy, Home Based Care programs are now a common response to HIV and AIDS.

According to Masthlaga $(2006,1)$ Community Home Based Care (CHBC) has received wider attention in Zimbabwe for its ability to provide a continuum of care for the chronically ill and PLWHA in their home environment. It provides services in a relatively cost effective, sustainable and comprehensive manner, in a complementary approach to institutional care. 
CHBC has therefore been hailed for reducing congestion in hospitals, thereby reducing health/hospital expenditures in the face of increasing number of chronically ill PLWHA, cancer, TB patients and other incurable illnesses. Apart from providing care and support to clients/patients, the programme also seeks to enhance or build the capacity of clients' families to offer affordable, quality care for their relative. Hall et al $(2006,3)$ further note that given the challenges facing Zimbabwe's health care system and the magnitude of the HIV and AIDS epidemic, HBC has emerged as the most viable option to meet the long term health needs of PLWA.

As a result $\mathrm{CHBC}$ is being seen as a way of reducing congestion in hospitals and reducing hospital expenditure in the face of high numbers of patients with incurable and chronic illness. According to Kachere $(208,4)$ countries in Africa are facing a serious public health meltdown as hundreds of public health workers are leaving the region in search of better paying remuneration. The HBC programmes traditionally have been providing physical, emotional, spiritual and palliative care to the chronically and terminally ill patients. Tikiwa (2008) also acknowledges that Home Based Care forms the backbone of care in Zimbabwe. However much of the work of HBC remains unpaid, unaccounted for and undervalued in economic terms despite its critical contribution to the overall economy and society in general. In Zimbabwe volunteer caregivers form the backbone of AIDS care in Zimbabwe even though they lack the basic resources they need to provide care for people with HIV. Ideally in the current challenges in the health care environment characterized by high staff shortages and limited resources this is definitely bound to threaten the survival of $\mathrm{CHBC}$ programme.

\section{Health Care In An Economy Under Siege}

Over the years despite nominal increases in budgetary allocations to the Ministry of Health and Child Welfare in real terms per capita allocations declined in the face of increasing demand for health services (ZHDR, 2003, 102). Furthermore according to ZHDR (2003, 36) while substantial progress was achieved during the 1990s the emergence of a growing budget deficit and threats of a stagnating economy forced the Zimbabwean government to abandon its interventionist and redistributive policies. In 1991 government adopted ESAP with its recommendations which called for more budgetary allocations to growth sectors as opposed to the consumptive sectors. The program called for the removal of subsidies on social services and basic commodities etc. As noted by Hall et al $(2006,1)$ progressive shortfalls in Government funding in the health sector have caused trained personnel in the health sector to flee the country in search for greener pastures in the Southern African Development Community (SADC) region and beyond as far as New Zealand. As a result the situation in the health sector has been made worse by the mass exodus of nursing staff to other countries in recent years due to the worsening economic situation. Currently all health institutions are operating at very low establishment levels. As a result of the immense burden and challenges facing the health delivery system one can argue that there has been a deliberate shift to Home Based Care and hospices for terminally ill patients 
In the context of the above as acknowledged by the Zimbabwe Human Development Report $(2003,5)$ there exists a gender dimension to poverty in Zimbabwe in which women are disproportionately affected. This is so because women largely constitute the infected, affected, poorest and natural caregivers under the epidemic. Infact the ZHDR $(2003,5)$ noted that;

"the plight of women requires special attention in the design of intervention strategies to combat the HIV and AIDS epidemic."

The result is that the above assertion in the face of HIV and AIDS in Zimbabwe and the serious challenges experienced in the health sector runs counter to the arguments put forward by reflexive modernist on the supposed progressive freeing of the individual from socio-cultural structural constraints. This is so because as more and more people take to Home Based Care it is women who bear the brunt of the epidemic as they are viewed as the natural caregivers in the care economy. Therefore this puts to question the thinking behind reflexive modernity as women instead of women being freed from traditional constraints they are once more being entangled in the care environment as they take care of their family members in the terminal and most taxing stage of HIV and AIDS.

\section{Conclusion}

As this paper has discussed high prevalence rates of HIV/AIDS in a non-performing economy like Zimbabwe is having an impact on female workload as women are becoming the main care givers under Home Based Care. The non performance of the economy has progressively led to serious brain drain as health personnel flock out of the country to look for better paying jobs in the region and abroad as a result of the poor salaries and not so conducive working conditions in the health sector at home. The challenges faced in the health delivery system and increasing adoption of Home Based Care as the paper puts across does question the arguments presented by theories of reflexive modernity considering the responsibilities that are disproportionately falling on women. Reflexive modernity theorists have argued that women are becoming increasingly freed from the constraining structures of tradition and becoming endowed with individual agency. As such the increasing adoption of Home Based Care as a palliative care strategy for HIV and AIDS patients in the terminal and most taxing stage of AIDS in Zimbabwe is increasing women's workload as women are assumed to be the natural caregivers for these patients in the home environment and therefore invalidating the arguments of reflexive modernity which argue that as societies move on there is increasingly a detachment from traditional obligations and constraints.

\section{References}

ARASA (2004). Proposed Code for The Southern African Development Community, ARASA, Windhoek.

Beck, U (1992). Risk Society: Towards a New Modernity, Sage, London. 
Beck, U and Beck, G (1996) Individualisation and "Precarious" Freedoms, Perspectives and Controversies of a Subject Oriented Sociology" in Heclas, P, Lash, S and Morris, P (eds), (1996). Detraditionalisation: Critical Reflections on Authority and Identity, Blackwell, Oxford.

Bildenberg, K, et al (2008). The Role of The Affected State in Humanitarian Action Case studies of Bangladesh and Zimbabwe, London, ODI, Unpublished LSE Dv406 Development Management Project 2008.

Government of Zimbabwe National Community and Home Based Care Strategic Plan 2010-2015, National Care and Support Programme, (2010)

Hall, C et al (2006). Man Enough to Care: Involving Men in Home Based Services for People Living with HIV/AIDS in Rural Zimbabwe, Office of Health and HIV/AIDS, Africare.

HelpAge International (1999). The Ageing and Development Report, Earthscan, London.

International Organisation for Migration (2009). The Impact of the Brain Drain on Health Service Delivery in Zimbabwe: A Response Analysis, IOM, Harare.

Kachere, P (2008). Africa Faces Public Health Collapse, Sunday Mail August 10-16 2008 pp4

Masthlaga, N (2006). National Review of Community Home Based Care and Access to Treatment Services in Zimbabwe

Mundia, M (2008). The Changing Landscape of Home-based Care Services in the Era of Widely Accessible ART in Zambia, 20-22, Canadian Journal of Public Health, 99, Supp 1, May/June 2008

Ogden, J, Esim, S and Grown, C (2006). Expanding the Care Continuum for HIV/AIDS: Bringing Carers Into Focus, 2006. Published by Oxford University Press in association with The London School of Hygiene and Tropical Medicine

The Herald, Tuesday 1 July, 2008, pp2

Zimbabwe Human Development Report 2003: Redirecting Our Responses to HIV and AIDS, (2003). PRF, Harare. 